\title{
MATHEMATICAL MODEL FOR VELOCITY CALCULATION OF THREE TYPES OF VEHICLES IN THE CASE OF PEDESTRIAN CRASH
}

\author{
HOXHA Gëzim¹, SHALA Ahmet ${ }^{1}$, LIKAJ Ramëํㅜ, BAJRAMI Xhevahir1 \\ ${ }^{1}$ University of Prishtina "Hasan Prishtina", Faculty of Mechanical Engineering, Department of Mechatronics, \\ Pristina, Bregu i Diellit, p.n.10000 Prishtinë, Kosovës, e-email: xhevahir.bajrami@uni-pr.edu
}

\begin{abstract}
This paper treats influencing factors in the determination of vehicles speed on the pedestrian crash moment according to pedestrian throw distance and formulates a mathematical model for vehicle speed determination. Vehicle speed is one of the highest causes of accidents. The mathematical model formulation (as the target of this paper) for velocity calculation, in the case of pedestrian accidents, presents great help and guidance to experts of this field when dealing with accident analysis that through accurate determination of this parameter to find other circumstances as close as possible to the technical process of pedestrian accidents. The target of this paper is to define a mathematical model formulation for vehicle velocity calculation in pedestrian crash moment depending on relevant parameters. For the purpose of model formulating, we have selected three cases of real accidents that involved vehicles ("Peugeot 307", "VW Golf" and "Mercedes E 220") with different geometrical parameters of the front profile and pedestrians with different heights and weights. For regression analysis we used "R" and "SPSS" software, which enables the statistical analysis of the data and mathematical model formulation. Also, for analysis of impact of relevant factors, model formulation and model testing have used "Virtual Crash" and "PC Crash" software, which enables pedestrian-vehicle crash simulation using vehicles with real technical characteristics and various pedestrian characteristics. Inductive, comparative, and deductive methods are part of the research methods in this paper.
\end{abstract}

KEYWORDS: vehicle, pedestrian, throw distance, friction, velocity

\section{Introduction}

The causes of the accidents are different, where extracted date includes the human factors, vehicle type, and road conditions as the main causes.

Vehicle-pedestrian accidents result in a considerable number all over the world and, in a lot of cases, are manifested with deadly injuries to pedestrians. A large number of accidents, not only fatal ones but also those with pedestrian injury and material damage of vehicles, have direct impact in traffic safety.

One of the highest causes of road accidents is the speed of vehicle, so determining vehicle speed is the most important analysis for finding the ultimate results regarding the cause and technical process of the accident. In this research, determining the problem of vehicle speed is treated based on data from the various concrete cases of traffic accidents.

For purposes of mathematical model formulation, are selected only the highest influential factors as: vehicle velocity, pedestrian length, pedestrian weight and friction. Then, by combining these factors through multiple linear regression, the mathematical model is formulated for determining vehicle speed at the moment of pedestrian impact. The mathematical model (as target of this research) is tested in concrete cases and obtained results are acceptable and reliable to over $95 \%$. 


\section{Characteristics of vehicles and pedestrians used in research}

From a large number of actual accidents expertise, several cases have been selected that have met the research conditions. These accidents have been involved with vehicles consisting of various technical characteristics and pedestrian with different ages.

A frontal hit is common for all cases of selected accidents for research is the way of pedestrian crash.

Table 1. Vehicles and pedestrians characteristics involved in real accidents used in research

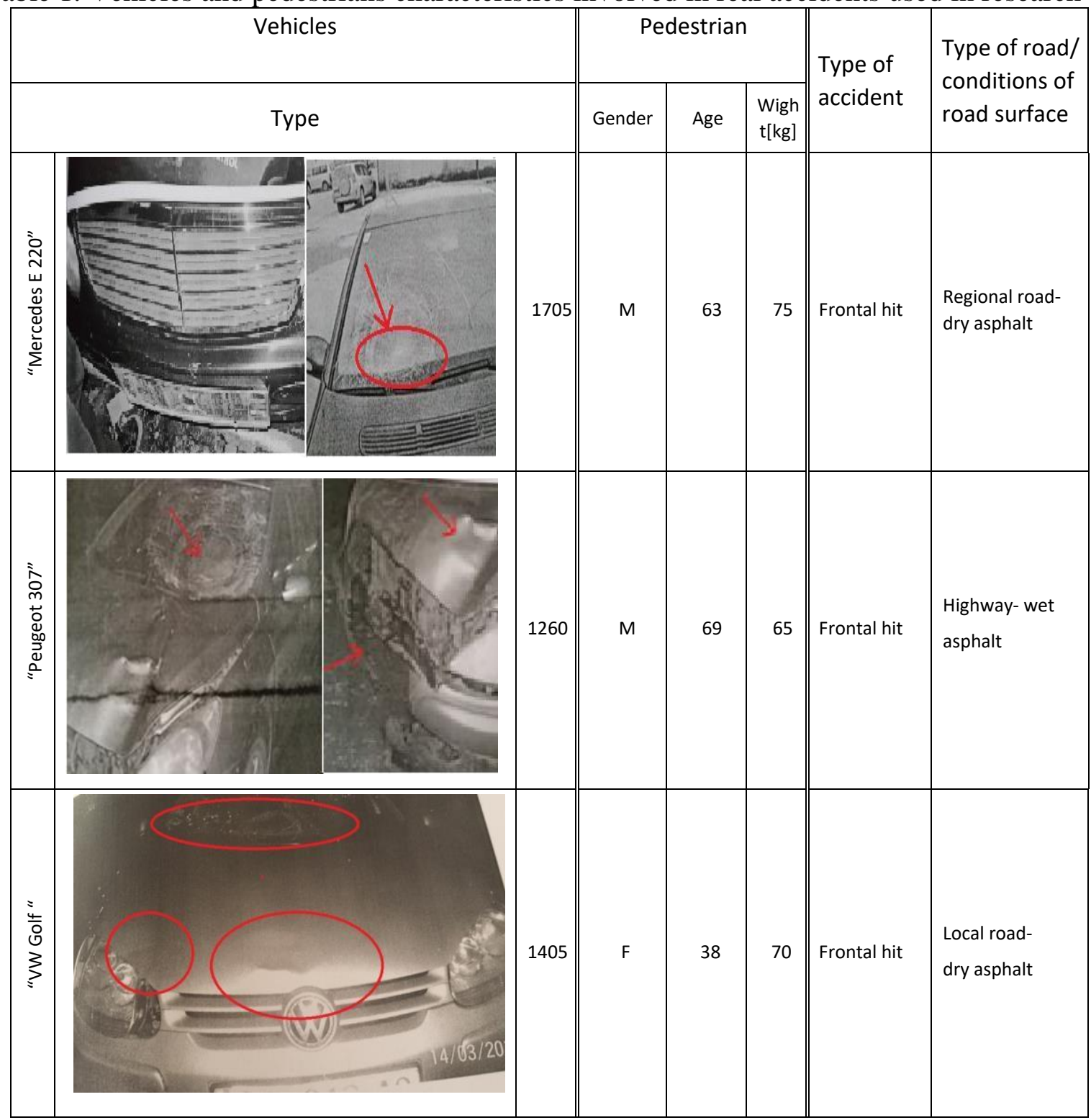

For these types of vehicles (Table 1.), and for the purpose of classifying and analysing the influence of front profile of the vehicle in the technical process of pedestrian crash, we measured some geometrical parameters of the front of these vehicles as distance of the front of the engine cover, edge height of the bumper, edge height of the vehicle front of the engine cover, the angle defined by the top of the bumper, and the front edge of the engine cover (Figure 1.). 


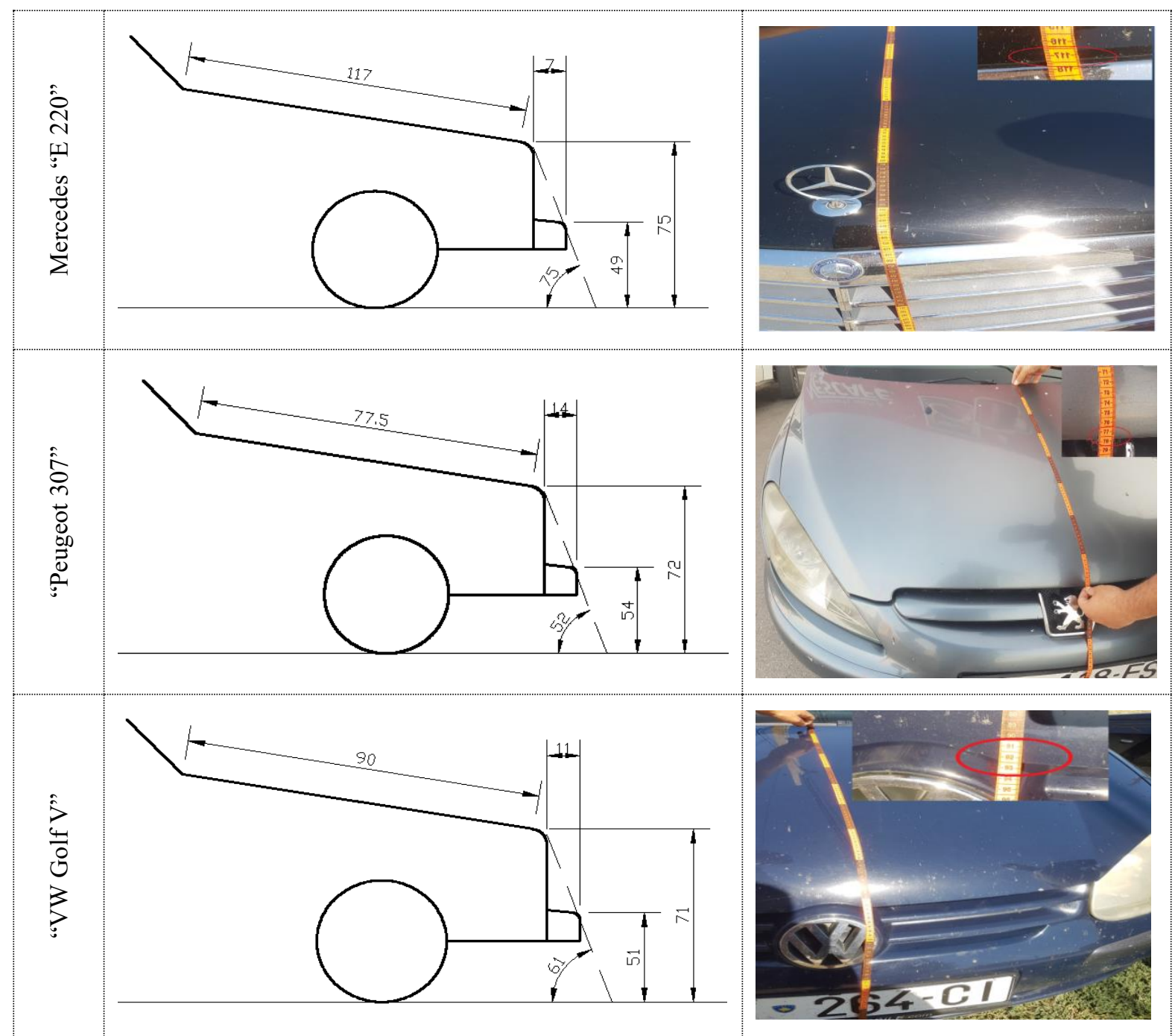

Fig. 1 Geometrical parameters of "Mercedes E220", "Peugeot 307" and "VW Golf V"

Depending on the angle between the edge of the engine cover and the edge of the front defender, as well as the distance of the front of the vehicles measured in real cases (Table 1.), vehicles are classified into three main groups (Table 2.).

Table 2. Classification of vehicles depending on the geometrical parameters of the frontal profile

\begin{tabular}{|l|c|c|c|c|c|}
\hline Vehicles & Gr. & $\begin{array}{l}\text { Edge height of the } \\
\text { vehicle front of the } \\
\text { engine cover [m] }\end{array}$ & $\begin{array}{l}\text { Edge height } \\
\text { of the } \\
\text { bumper [m] }\end{array}$ & $\begin{array}{l}\text { Distance of } \\
\text { the front of } \\
\text { the engine } \\
\text { cover [m] }\end{array}$ & $\begin{array}{l}\text { The angle defined } \\
\text { by the top of the } \\
\text { bumper and the } \\
\text { front edge of the } \\
\text { engine cover [ }\end{array}$ \\
\hline "Peugeot 307" & I & 0.72 & 0.54 & 0.77 & $50^{\circ}<\alpha<60^{\circ}$ \\
\hline "VW Golf V" & II & 0.71 & 0.51 & 0.90 & $60^{\circ}<\alpha<70^{\circ}$ \\
\hline "Mercedes E 220" & III & 0.75 & 0.49 & 1.17 & $70^{\circ}<\alpha<80^{\circ}$ \\
\hline
\end{tabular}


The technical process of the pedestrian-vehicle crash, respectively, the frontal collision of the pedestrian vehicle is not always the same. Identified factors with the greatest impact on the length of pedestrian throw are:

- Geometrical parameters of the front vehicle profile;

- Vehicle velocity;

- Height of pedestrian;

- Weight of pedestrian;

- Road friction.

Parameters with lower impact are not included in the model formulation.

Based on the geometrical characteristics of frontal vehicle profile, such as distance of the front of the engine cover, edge height of the bumper, edge height of the vehicle front of the engine cover, the angle defined by the top of the bumper, and the front edge of the engine cover (Figure 1. and Table 2.), are realized simulation tests using Virtual Crash software. "Virtual Crash 4" software, for this purpose, assumes a "multibody" pedestrian model which can be a good tool for analysing pedestrian movement regarding its kinematic and dynamic influence. The model also includes the ability to use different types of pedestrians (with different lengths and different weights) under different conditions before crashing (pedestrian in stop, walk, running, different positions).

With the use of the Virtual Crash 4 software with a "multibody" system, it has also become possible to link pedestrian injuries to damages in vehicles. The elements of the "multibody" pedestrian body (head, upper extremity, pelvis, lower extremity, etc.) are connected to the joints. For each body there are different characteristics, such as geometry, mass, contact hardness, and friction coefficient.

\section{Test - Simulations}

\section{Veh. "Mercedes"}

The frontal profile of the vehicle has impact in vehicle-pedestrian crash due to different types of profile vehicles, the ratio between the impact point in the vehicle, and the pedestrian centre is different. It is characteristic that during the collision, the pedestrian body immediately at the moment of collision reaches the speed of the vehicle. For small trapezoidal or ellipsoidal vehicles (Mercedes, Peugeot and VW Golf), the impact centre of the vehicle front is located beneath the pedestrian body weighing centre and, consequently, have the effect of passing the pedestrian from the vehicle or throwing it over vehicle (Figure 2.).

Throw model to these cases (when in the crash process include vehicles from groups I, II and III) takes into account pedestrian movements during the three phases:

- Hit and throw of pedestrian body in frontal vehicle part (common distance of movement of pedestrian and vehicle);

- Height throw ("flying”) of pedestrian body;

- Sliding until final position of pedestrian. 


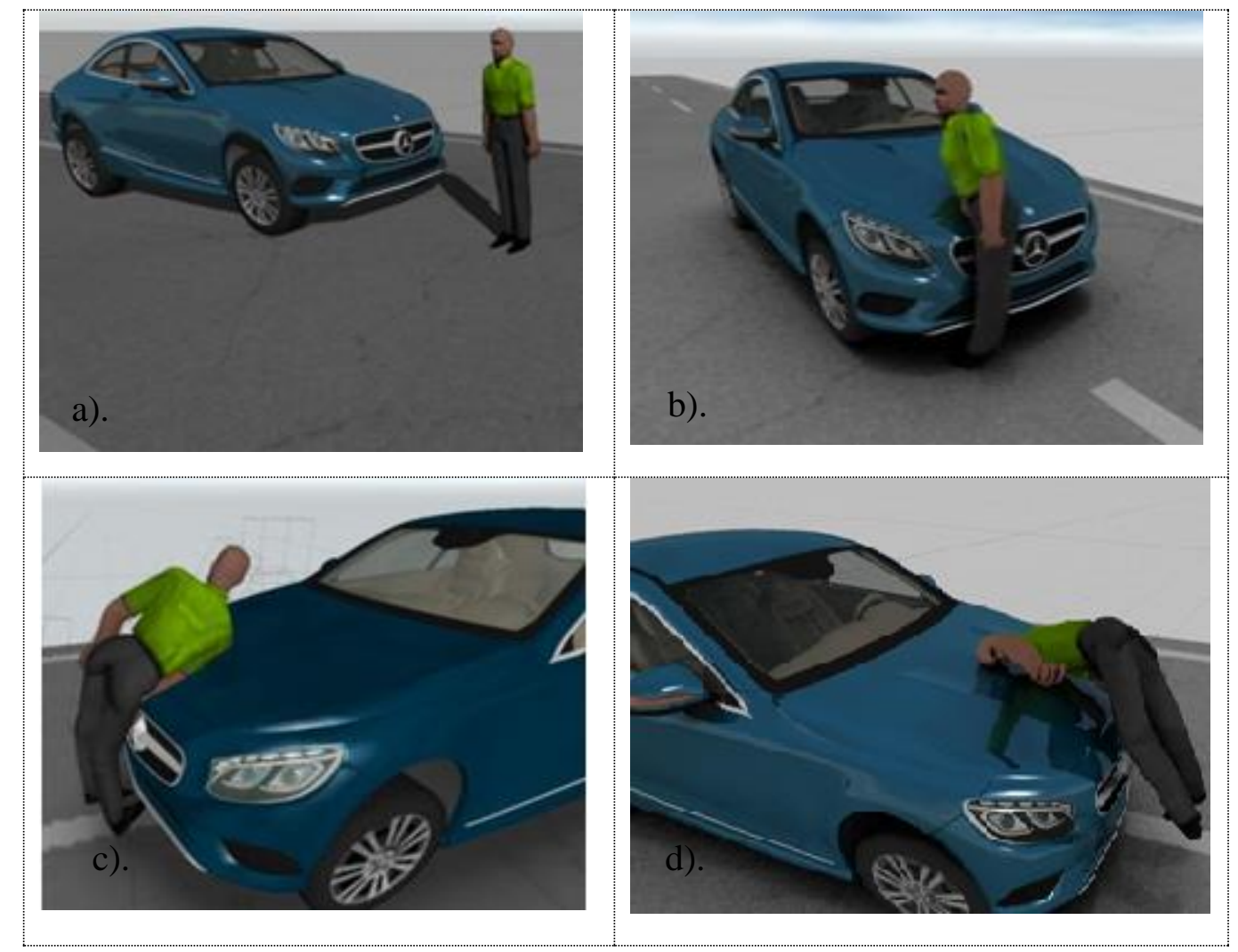

Fig. 2 Stages of body throwing in the vehicle

Tests of pedestrian hit from vehicle "Mercedes E 220" for value of friction $\mu=0.1$ and 0.2 are shown in Figure 3 and Figure 4.

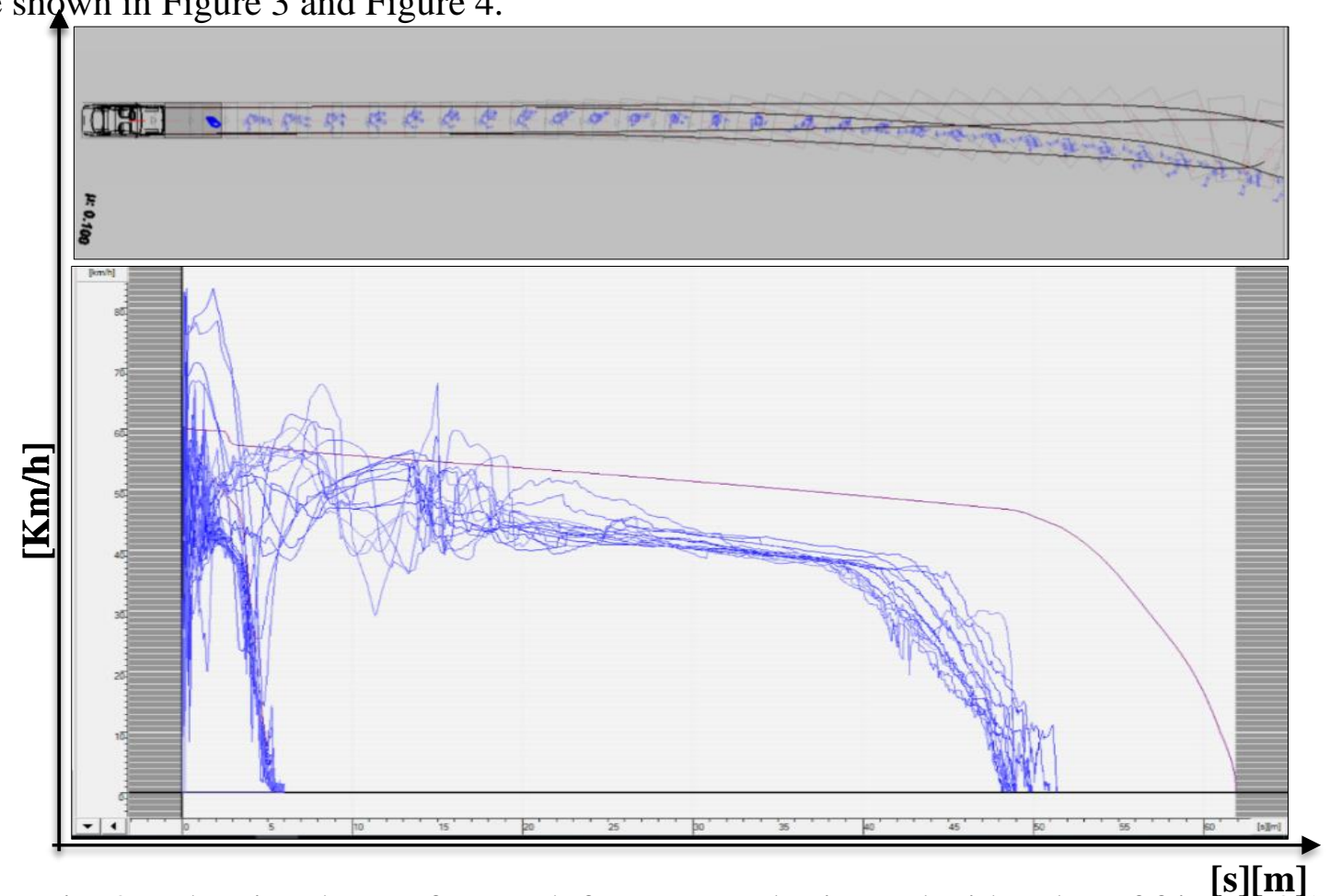

Fig. 3 Pedestrian throw after crash from Mercedes in road with value of friction 0.1 


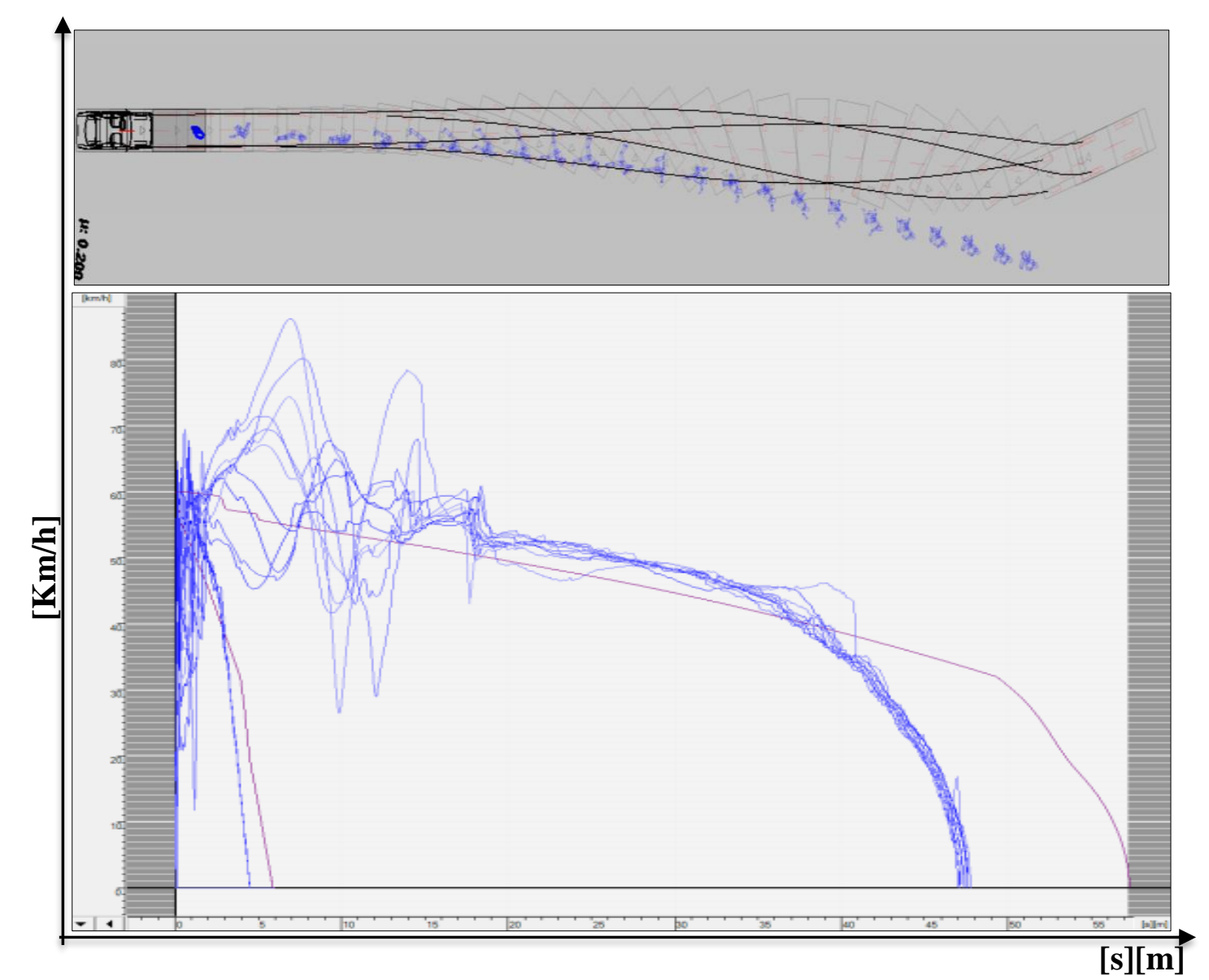

Fig. 4 Pedestrian throw after crash from Mercedes in road with value of friction 0.2

Results of pedestrian hit tests from vehicles classified in groups I, II and III with ellipsoid and trapezoid profile shown that final position of pedestrian is large when value of friction is reduced. For lower values of friction $(0.1,0.2,0.3$ until 0.35$)$, the vehicle break is lower so, as a result, the inertia acting force in pedestrian after hit moment is lower. For these reasons pedestrian movement is common with the vehicle frontal until the stop position and has not thrown the pedestrian. Correlation of dependency of the thrown pedestrian distance from friction is not good for lower values of friction (under 0.35), so, in this case the total distance of pedestrian throw cannot be taken as a basis for calculating the speed of the vehicle.

\section{Test-Simulation "Peugeot 307"}
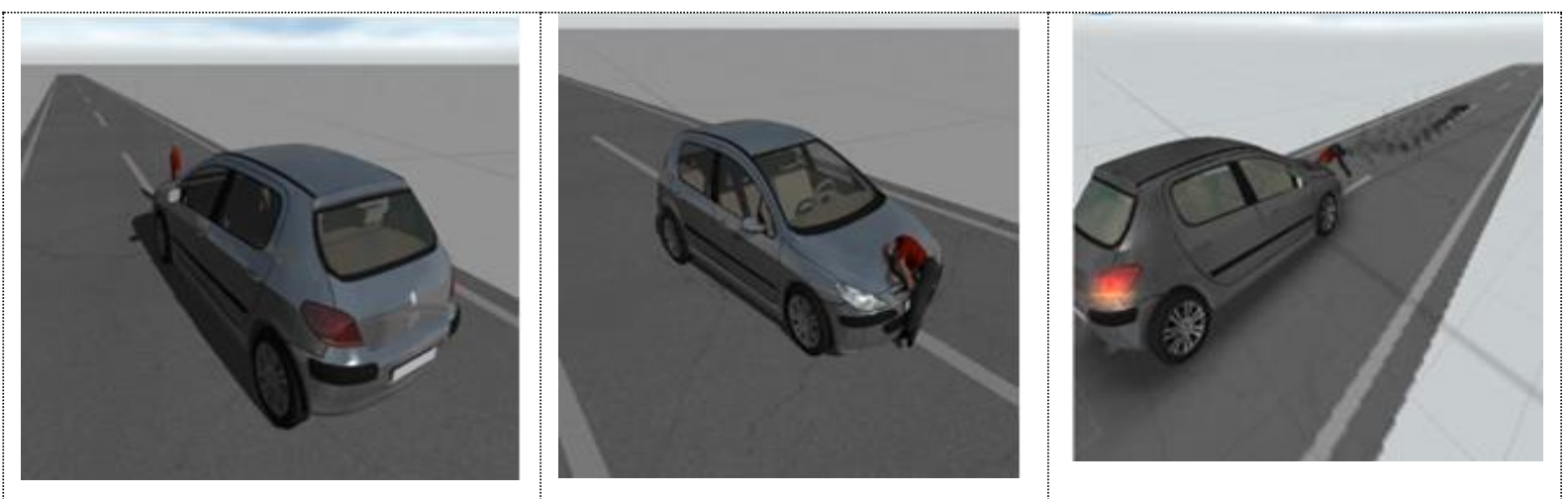

Fig. 5 Test-simulation of crash "Child- Peugeot 307"

Diagram 1. Velocity- throw distance-time 

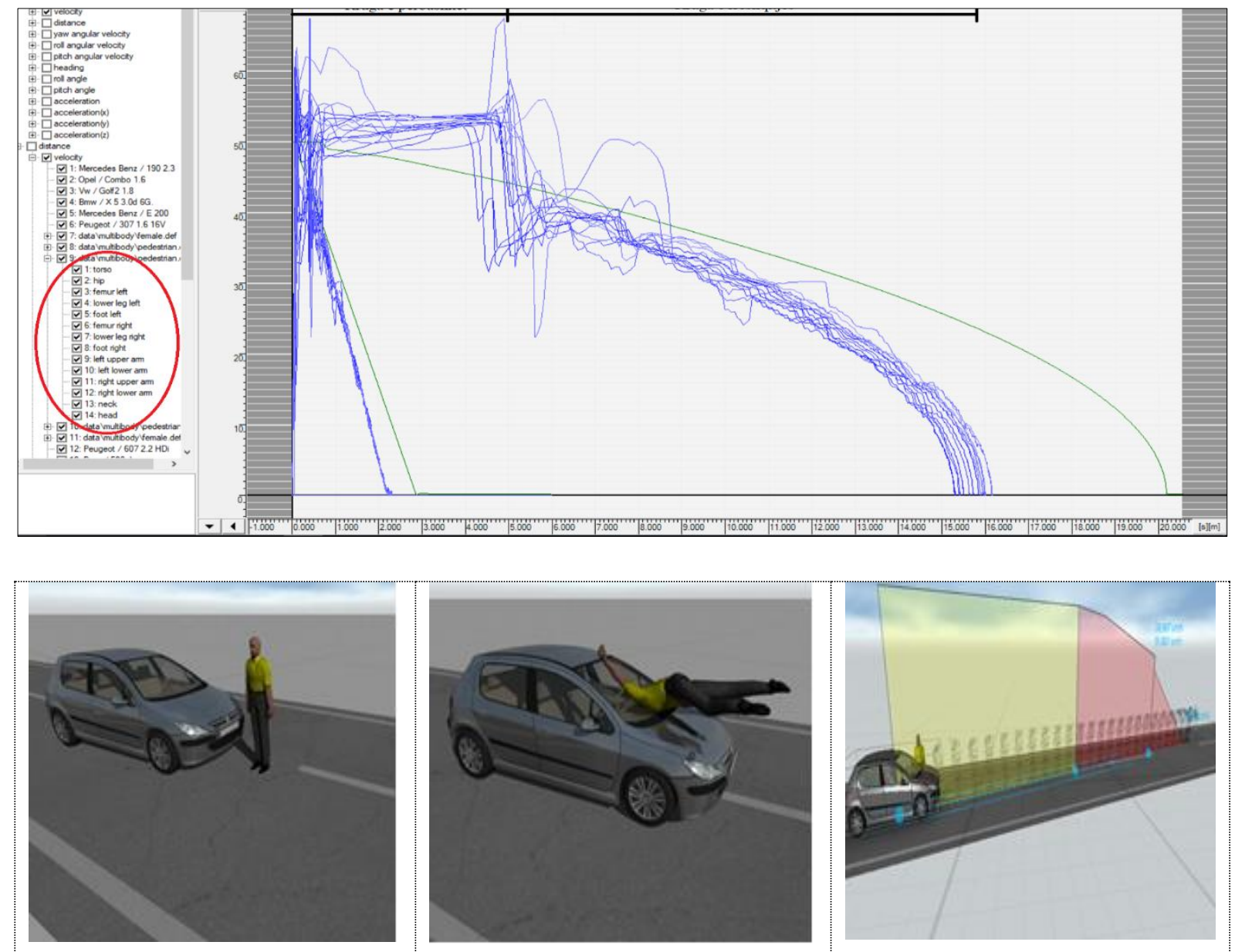

Fig. 6 Test-simulation of crash "Adult pedestrian- Peugeot 307"

For adult pedestrians, following the moment of the primary hit, the possibility of the pedestrian throwing on the front of the engine cover and the glass of the vehicle has increased. The common pedestrian and vehicle movement in this case is greater when compared to the child crash case. Increasing the length of the pedestrian means a proportional increase of its weight, which has an impact on the pedestrian collision kinematics that ultimately increases in the total length of pedestrian throwing.

1. $\mathrm{L}_{\mathrm{k}}=1.1 \mathrm{~m}, \mathrm{P}_{\mathrm{k}}=23 \mathrm{~kg}, \mathrm{GJ}-\mathrm{F}, \mathrm{v}=50 \mathrm{~km} / \mathrm{h}, \mathrm{L}_{\mathrm{HVw}}=14.5 \mathrm{~m}$
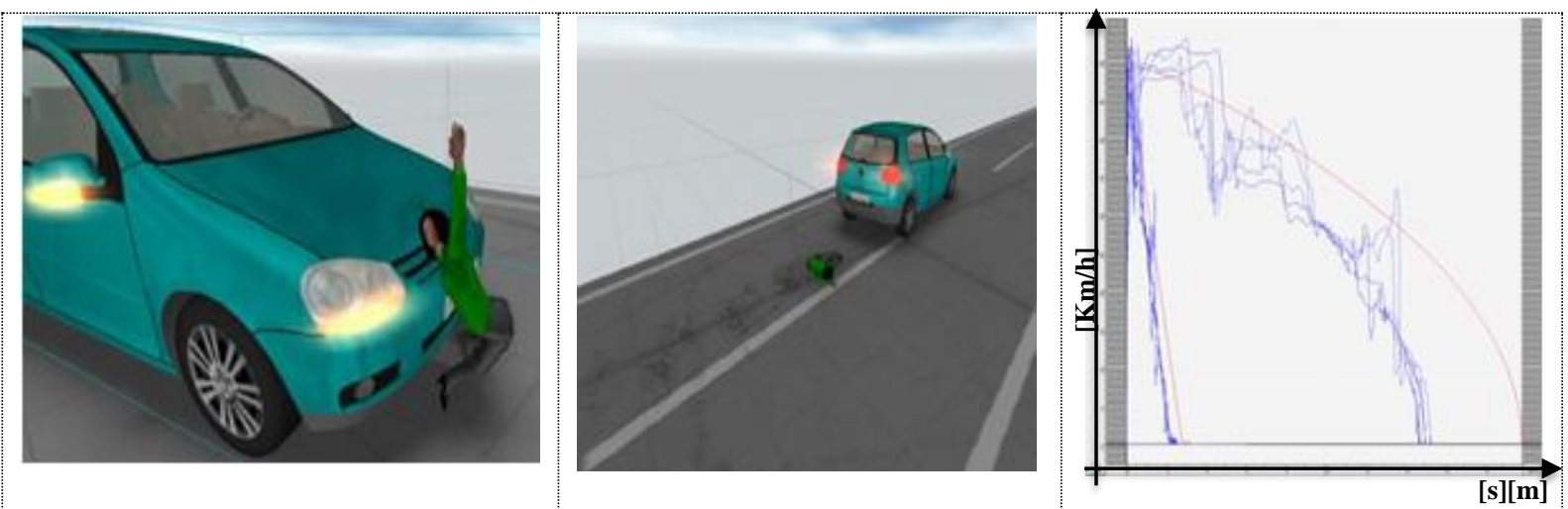

Fig. 7 Test simulation of crash "Adult pedestrian - VW Golf V"

2. $\mathrm{L}_{\mathrm{k}}=1.22 \mathrm{~m}, \mathrm{P}_{\mathrm{k}}=32 \mathrm{~kg}, \mathrm{GJ}-\mathrm{F}, \mathrm{v}=50 \mathrm{~km} / \mathrm{h}, \mathrm{L}_{\mathrm{H}}=15.5 \mathrm{~m}$ 


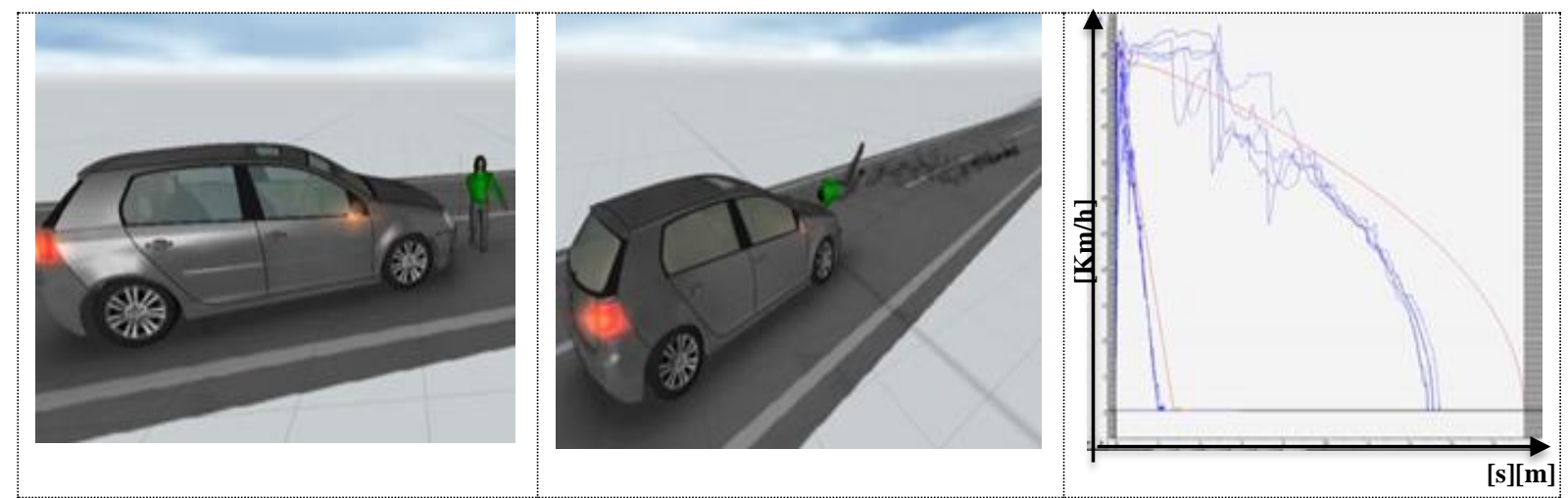

Fig. 8 Test simulation of crash "Adult pedestrian- VW Golf V"

$3 . \mathrm{L}_{\mathrm{k}}=1.65 \mathrm{~m}, \mathrm{P}_{\mathrm{k}}=58 \mathrm{~kg}, \mathrm{GJ}-\mathrm{F}, \mathrm{v}=50 \mathrm{~km} / \mathrm{h}, \mathrm{L}_{\mathrm{HVw}}=22 \mathrm{~m}$

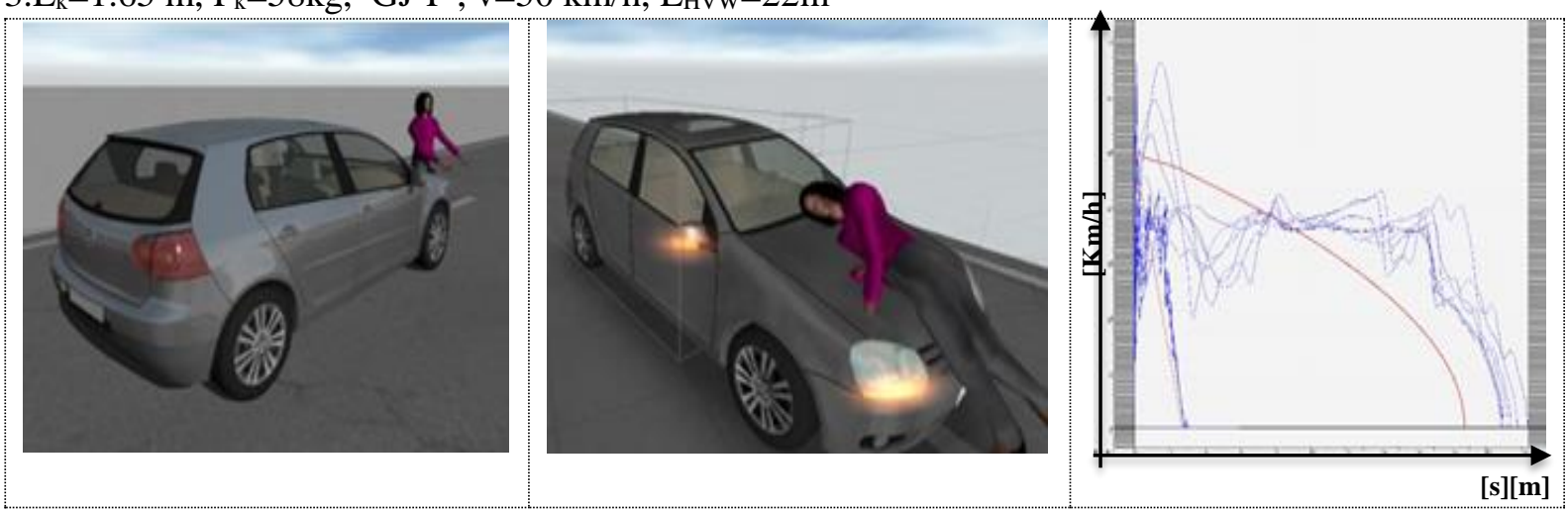

Fig. 9 Test simulation of crash "Adult pedestrian- VW Golf V"

\section{Mathematical model for vehicle speed determination in the case of frontal pedestrian crash}

Results obtained from test simulations of pedestrians hit from vehicles "Mercedes E220", "Peugeot 307", and "VW Golf V" prove that the technical process of the pedestrian-vehicle crash, respectively frontal vehicle-pedestrian process has some different specifics. Identified factors with the greatest impact on the length of pedestrian throw are:

- Geometrical parameters of front vehicle profile;

- Vehicle velocity $\left(v_{g}\right)$;

- Height of pedestrian $\left(L_{k}\right)$;

- Weight of pedestrian $\left(P_{k}\right)$;

- Roadfriction $(\mu)$.

Below are identified combinations of these factors, including values different from the selected factors $\mu, \mathrm{Lk}, \mathrm{Pk}$, and $\mathrm{vg}$ (as independent variables) and results from the pedestrian throwing length analysis (as a dependent variables). The obtained results are presented in Table 3. 
Table 3. Results obtained from factors combination influencing in pedestrian throw distance

\begin{tabular}{|c|c|c|c|c|c|c|c|}
\hline \multirow[b]{2}{*}{$\mu$} & \multirow[b]{2}{*}{$L_{k}[m]$} & \multirow[b]{2}{*}{$\begin{array}{c}P_{k} \\
{[\mathrm{~kg}]}\end{array}$} & \multirow[b]{2}{*}{$v_{g}[\mathrm{~km} / \mathrm{h}]$} & \multicolumn{4}{|c|}{ Pedestrian throw distance- $L_{H}[m]$} \\
\hline & & & & $\begin{array}{c}\text { "Peugeot } \\
307 " \\
\left(\alpha=52^{\circ}\right) \\
\text { GR.I }\end{array}$ & $\begin{array}{c}\text { "VW Golf } \\
19 \mathrm{E} " \\
\left(\alpha=67^{0}\right) \\
G r . I I\end{array}$ & $\begin{array}{c}\text { "Mercedes E } \\
220^{\prime} " \\
\left(\alpha=75^{\circ}\right) \\
\text { GR.III }\end{array}$ & \\
\hline 0.78 & 1.78 & 75 & 60 & 24 & 23 & 24 & 23.66667 \\
\hline 0.7 & 1.78 & 75 & 60 & 25 & 25 & 26 & 25.33333 \\
\hline 0.6 & 1.78 & 75 & 60 & 26.5 & 26 & 27 & 26.5 \\
\hline 0.5 & 1.78 & 75 & 60 & 29 & 29 & 32 & 30 \\
\hline 0.4 & 1.78 & 75 & 60 & 32 & 32 & 33.5 & 32.5 \\
\hline 0.78 & 1.78 & 75 & 20 & 4.5 & 4.5 & 6 & 5 \\
\hline 0.78 & 1.78 & 75 & 30 & 9 & 8.5 & 12 & 9.833333 \\
\hline 0.78 & 1.78 & 75 & 40 & 13 & 14 & 18 & 15 \\
\hline 0.78 & 1.78 & 75 & 50 & 18 & 20 & 24 & 20.66667 \\
\hline 0.78 & 1.78 & 75 & 60 & 25 & 23 & 25 & 24.33333 \\
\hline 0.78 & 1.78 & 75 & 70 & 29 & 27 & 28 & 28 \\
\hline 0.78 & 1.78 & 75 & 80 & 33 & 35 & 35 & 34.33333 \\
\hline 0.78 & 1.78 & 75 & 90 & 43 & 40 & 45 & 42.66667 \\
\hline 0.78 & 0.96 & 19 & 50 & 15 & 15 & 16 & 15.33333 \\
\hline 0.78 & 1.1 & 23 & 50 & 17 & 17 & 17 & 17 \\
\hline 0.78 & 1.22 & 32 & 50 & 17.5 & 19 & 18 & 18.16667 \\
\hline 0.78 & 1.35 & 35 & 50 & 18 & 19 & 20 & 19 \\
\hline 0.78 & 1.65 & 58 & 50 & 18 & 19.5 & 21.5 & 19.66667 \\
\hline 0.78 & 1.0 & 25 & 50 & 15 & 14 & 16 & 15 \\
\hline 0.78 & 1.15 & 30 & 50 & 16 & 16 & 17.5 & 16.5 \\
\hline 0.78 & 1.25 & 35 & 50 & 17 & 18 & 18.5 & 17.83333 \\
\hline 0.78 & 1.38 & 42 & 50 & 18 & 19 & 20 & 19 \\
\hline 0.78 & 1.45 & 45 & 50 & 18 & 20 & 22 & 20 \\
\hline 0.78 & 1.78 & 75 & 50 & 18 & 20 & 22 & 20 \\
\hline 0.7 & 1.78 & 75 & 20 & 5 & 5 & 6.5 & 5.5 \\
\hline 0.6 & 1.78 & 75 & 30 & 9 & 9 & 9 & 9 \\
\hline 0.5 & 1.78 & 75 & 40 & 15 & 16 & 14.5 & 15.16667 \\
\hline 0.4 & 1.78 & 75 & 50 & 26 & 28 & 29 & 27.66667 \\
\hline 0.6 & 1.78 & 75 & 10 & 3 & 3 & 2.5 & 2.833333 \\
\hline 0.6 & 1.78 & 75 & 15 & 3.5 & 4 & 4 & 3.833333 \\
\hline 0.6 & 1.78 & 75 & 20 & 4.5 & 5 & 5.5 & 5 \\
\hline 0.6 & 1.78 & 75 & 25 & 7 & 6.5 & 8 & 7.166667 \\
\hline 0.6 & 1.78 & 75 & 30 & 9 & 8.5 & 9 & 8.833333 \\
\hline 0.6 & 1.78 & 75 & 35 & 12 & 11 & 11 & 11.33333 \\
\hline 0.6 & 1.78 & 75 & 40 & 14 & 14 & 14.5 & 14.16667 \\
\hline 0.6 & 1.78 & 75 & 45 & 15.5 & 15 & 18 & 16.16667 \\
\hline 0.6 & 1.78 & 75 & 50 & 20 & 21 & 22 & 21 \\
\hline 0.6 & 1.78 & 75 & 55 & 23.5 & 22 & 25 & 23.5 \\
\hline 0.6 & 1.78 & 75 & 60 & 28 & 26 & 26 & 26.66667 \\
\hline 0.6 & 1.78 & 75 & 65 & 31 & 29 & 30 & 30 \\
\hline 0.6 & 1.78 & 75 & 70 & 32 & 30 & 30 & 30.66667 \\
\hline 0.6 & 1.78 & 75 & 75 & 37 & 35 & 36 & 36 \\
\hline 0.6 & 1.78 & 75 & 80 & 39 & 41 & 45 & 41.66667 \\
\hline 0.6 & 1.78 & 75 & 85 & 45 & 43 & 48.5 & 45.5 \\
\hline 0.6 & 1.78 & 75 & 90 & 48 & 46 & 52 & 48.66667 \\
\hline 0.4 & 1.78 & 75 & 10 & 2.5 & 3 & 2.5 & 2.666667 \\
\hline 0.4 & 1.78 & 75 & 15 & 4 & 4 & 3.5 & 3.833333 \\
\hline
\end{tabular}




\begin{tabular}{|l|l|l|l|c|c|c|c|}
\hline 0.4 & 1.78 & 75 & 20 & 5.5 & 5.5 & 6 & 5.666667 \\
\hline 0.4 & 1.78 & 75 & 25 & 8 & 8 & 8 & 8 \\
\hline 0.4 & 1.78 & 75 & 30 & 11.5 & 11 & 12 & 11.5 \\
\hline 0.4 & 1.78 & 75 & 35 & 14 & 14 & 16 & 14.66667 \\
\hline 0.4 & 1.78 & 75 & 40 & 18 & 19 & 19.5 & 18.83333 \\
\hline 0.4 & 1.78 & 75 & 45 & 20 & 22 & 22.5 & 21.5 \\
\hline 0.4 & 1.78 & 75 & 50 & 26 & 28 & 29 & 27.66667 \\
\hline 0.4 & 1.78 & 75 & 55 & 27 & 32 & 33 & 30.66667 \\
\hline 0.4 & 1.78 & 75 & 60 & 32 & 33 & 37.5 & 34.16667 \\
\hline 0.4 & 1.78 & 75 & 65 & 33 & 41 & 45 & 39.66667 \\
\hline 0.4 & 1.78 & 75 & 70 & 41 & 44 & 45 & 43.33333 \\
\hline 0.4 & 1.78 & 75 & 75 & 48 & 48 & 47 & 47.66667 \\
\hline 0.4 & 1.78 & 75 & 80 & 54 & 52 & 50 & 52 \\
\hline 0.4 & 1.78 & 75 & 85 & 54 & 56 & 58 & 56 \\
\hline 0.4 & 1.78 & 75 & 90 & 60 & 57 & 62 & 59.66667 \\
\hline
\end{tabular}

In a concrete case we have the incorporation of four independent variables (friction, pedestrian length, pedestrian weight, and vehicle velocity). In the application of multiple linear regression it is very important: to analyse the distribution of these data (multicolinearity) that create variables between them, the relation between dependent and independent variables, variance analysis (ANOVA test), etc.

A phenomenon that can be manifested in the case of multiple connection is the autocorrelation that explains the independence of the errors (is there a correlation between possible errors), so it is necessary to avoid this problem.

From analysis of data distribution (Diagrams 2 and 3), it can be noticed that the data has a normal distribution (curve in bell form).

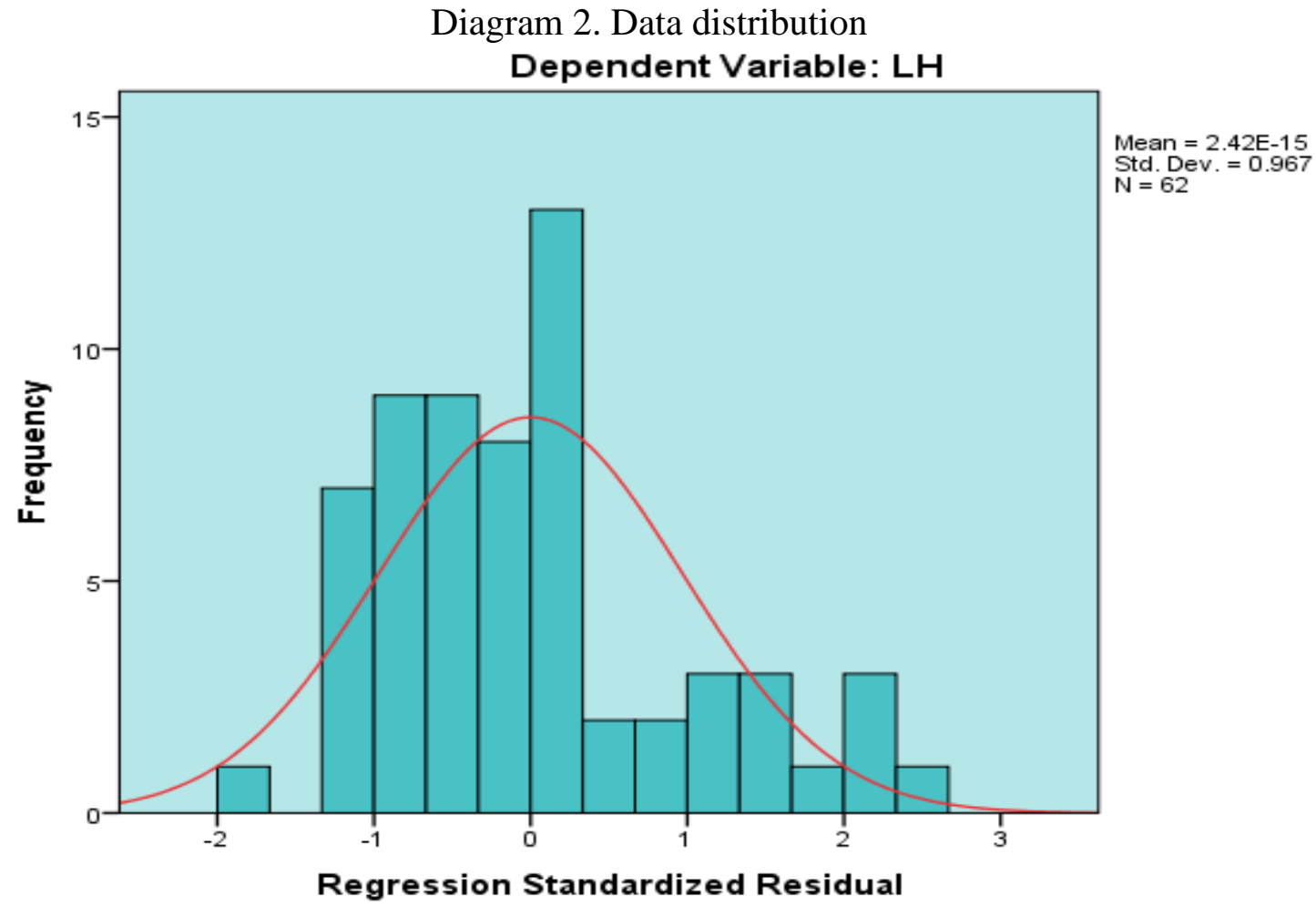

The data are distributed near normal as shown between -1,96 and +1,96 (Diagram 3.) and, also, they create a strong correlation and continuous linear dependence. Positive value (Diagram 2.) data are shown on the right, while negative value data are shown on the left. 
$\mathrm{R} 2=0.962$ in Diagram 3. show strong correlation between dependent variable (throw distance of pedestrian, LH) and independent variables (Vehicle velocity, $v g$, length of pedestrian, $L k$, weight of pedestrian, $P k$, and road friction, $\mu$ ).

Diagram 3. Correlation between depended variable and independent variables

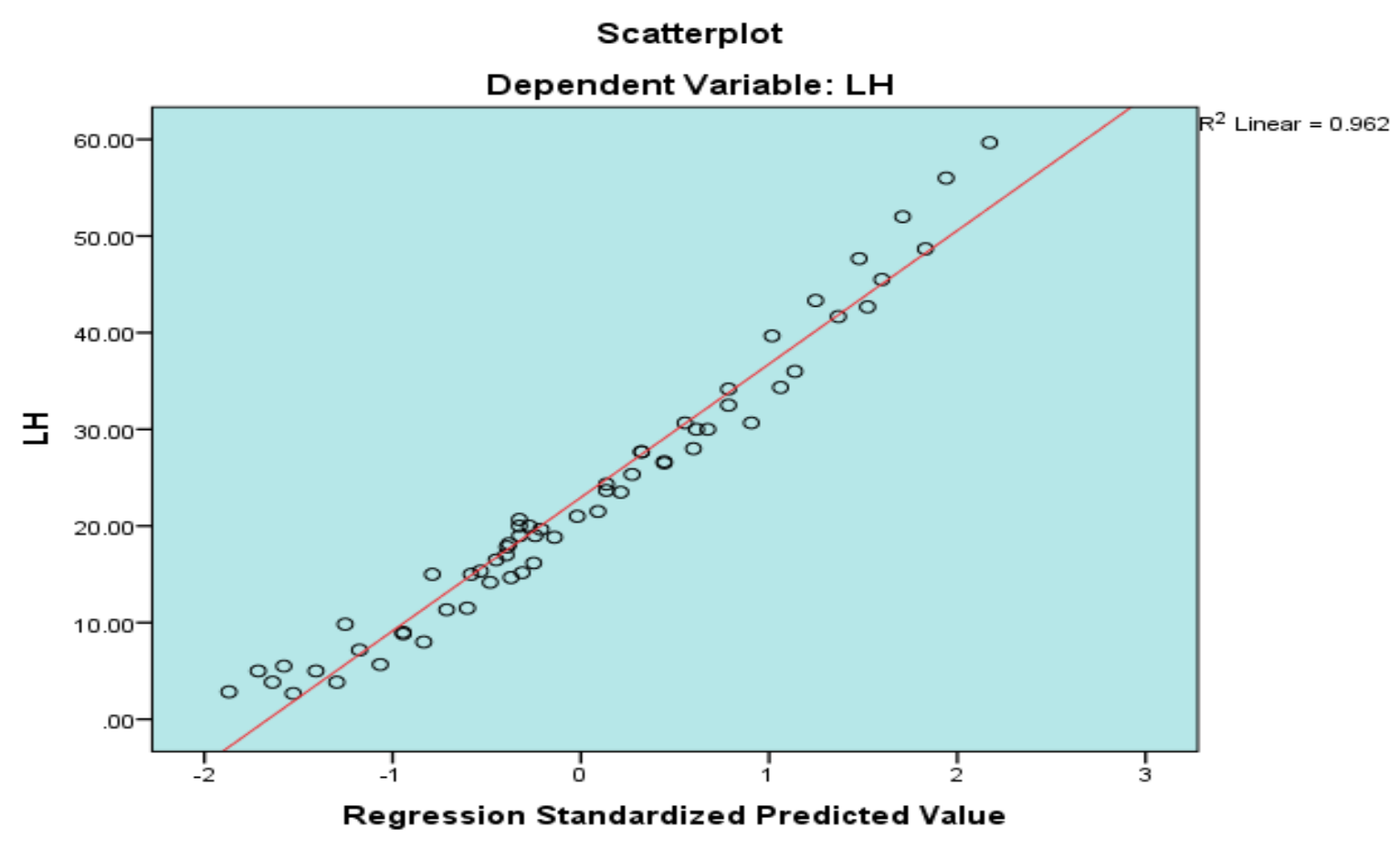

Table 4. Variables Entered/Removed

\begin{tabular}{|l|l|l|l|}
\hline Model & \multicolumn{1}{|c|}{$\begin{array}{c}\text { Variables } \\
\text { Entered }\end{array}$} & $\begin{array}{c}\text { Variables } \\
\text { Removed }\end{array}$ & Method \\
\hline 1 & $\begin{array}{l}\text { Velocity, Lk, } \mu, \\
\text { Weight }\end{array}$ & & Enter \\
\hline
\end{tabular}

a. Dependent Variable: $L_{H}$

b. All requested variables entered. 
Table 5. Model Summary

\begin{tabular}{|c|c|c|c|c|c|c|c|c|c|c|}
\hline \multirow[b]{2}{*}{$\begin{array}{l}\text { Mod } \\
\text { el }\end{array}$} & \multirow[b]{2}{*}{$\mathrm{R}$} & \multirow[b]{2}{*}{$\begin{array}{c}\mathrm{R} \\
\text { Square }\end{array}$} & \multirow[b]{2}{*}{$\begin{array}{c}\text { Adjusted R } \\
\text { Square }^{1}\end{array}$} & \multirow{2}{*}{$\begin{array}{l}\text { Std. Error } \\
\text { of the } \\
\text { Estimate }\end{array}$} & \multicolumn{5}{|c|}{ Change Statistics } & \multirow[b]{2}{*}{$\begin{array}{l}\text { Durbin- } \\
\text { Watson }\end{array}$} \\
\hline & & & & & $\begin{array}{c}\text { R Square } \\
\text { Change }\end{array}$ & $\begin{array}{c}\mathrm{F} \\
\text { Change }\end{array}$ & df1 & $\mathrm{df} 2$ & $\begin{array}{c}\text { Sig. F } \\
\text { Change }\end{array}$ & \\
\hline 1 & $.981^{a}$ & .962 & .960 & 2.82689 & .962 & 363.935 & 4 & 57 & .000 & .496 \\
\hline
\end{tabular}

a. Predictors: (Constant), Velocity, Lk, $\mu$, Weight

b. Dependent Variable: $\mathrm{LH}_{\mathrm{H}}$

In the Model Summary Table the "R Square" is important as illustrates the \% of dependent variable as explained by independent variables. In the concrete case from Table 5, R Square $=0.962$ which proves that a strong correlation between dependent variables and the unrelated variables exist, thus, $96.2 \%$ of the change in the dependent variables explain by independent variables. While the remaining 3.8\% explains variables that are not included in the model. From Table 5, the "Durbin Watson" coefficient is 0.496, which means that the likelihood of autocorrelation is very small and, if presented, they will be positive meaning that the standard error of coefficient " $b$ " is very small.

Table 6. ANOVA

\begin{tabular}{|c|c|c|c|c|c|c|}
\hline \multicolumn{2}{|c|}{ Model } & Sum of Squares & df & Mean Square & $\mathrm{F}$ & Sig. \\
\hline \multirow[t]{3}{*}{1} & Regression & 11633.283 & 4 & 2908.321 & 363.935 & $.000^{\mathrm{b}}$ \\
\hline & Residual & 455.505 & 57 & 7.991 & & \\
\hline & Total & 12088.788 & 61 & & & \\
\hline
\end{tabular}

a. Dependent Variable: LH

b. Predictors: (Constant), velocity, Lk, $\mu$, weight (Pk).

The ANOVA table it is useful to test the importance of the model as a whole. The F value in Table $6(\mathrm{~F}=363.935)$ shows that our model is important in each level as a whole (Sig.=,000.)

Table 7.Coefficients

\begin{tabular}{|c|c|c|c|c|c|c|c|c|}
\hline \multirow{2}{*}{\multicolumn{2}{|c|}{ Model }} & \multicolumn{2}{|c|}{ Unstandardized Coefficients } & \multirow{2}{*}{$\begin{array}{c}\text { Standardized } \\
\text { Coefficients } \\
\text { Beta } \\
\end{array}$} & \multirow[b]{2}{*}{$\mathrm{t}$} & \multirow[b]{2}{*}{ Sig. } & \multicolumn{2}{|c|}{ Collinearity Statistics } \\
\hline & & $\mathrm{B}$ & Std. Error & & & & Tolerance & VIF \\
\hline 11 & $\begin{array}{l}\text { (Consta } \\
\text { nt) }\end{array}$ & -12.946 & 10.496 & & -1.233 & .222 & & \\
\hline & $\mu$ & -23.579 & 2.747 & -.258 & -8.584 & .000 & .732 & 1.366 \\
\hline & Lk & 20.565 & 13.348 & .310 & 1.541 & .129 & .016 & 61.396 \\
\hline & $\mathrm{Pk}$ & -.250 & .183 & -.279 & -1.368 & .177 & .016 & 62.935 \\
\hline & Velocity & .639 & .017 & .949 & 36.882 & .000 & .999 & 1.001 \\
\hline
\end{tabular}

a. Dependent Variable: LH

From the results of the analysis of the importance of the coefficients (Table 7) it has been shown that the most important coefficients in the model are speed (Sig. $=0.000)$ and friction

\footnotetext{
${ }^{1}$ Adjusted R Square- Koeficienti i rregulluar i "R square" 
(Sig.=0.000). The mathematical model for vehicle speed calculation (Gr. I, II, and III) in the case of frontal pedestrian crash, obtained by multiple linear regression, has this form (2):

$$
\begin{aligned}
L_{H}=-12.94-23.579 \cdot \mu+20.56 \cdot L_{k}-0.250 \cdot P_{k}+0.639 \cdot v_{g} \\
\\
\mathrm{v}_{\mathrm{g}}=20.2+\frac{\mathrm{L}_{\mathrm{H}}+23.576 \cdot \mu-20.56 \cdot \mathrm{L}_{\mathrm{k}}+0.25 \cdot \mathrm{P}_{\mathrm{k}}}{0.639}
\end{aligned}
$$

\section{Testing of model validity in concrete cases of accidents in practice}

The validity of the formulated model in the case of pedestrians hit by "Mercedes E220", "Peugeot 307" and "VW Golf" vehicles has been tested in concrete cases of accidents in practice. The results obtained in all cases were acceptable, with the possibility of a deviation of $+/-5 \%$ (Tables 8 and 9 ).

Table 8. Test of model - Case of "Mercedes"

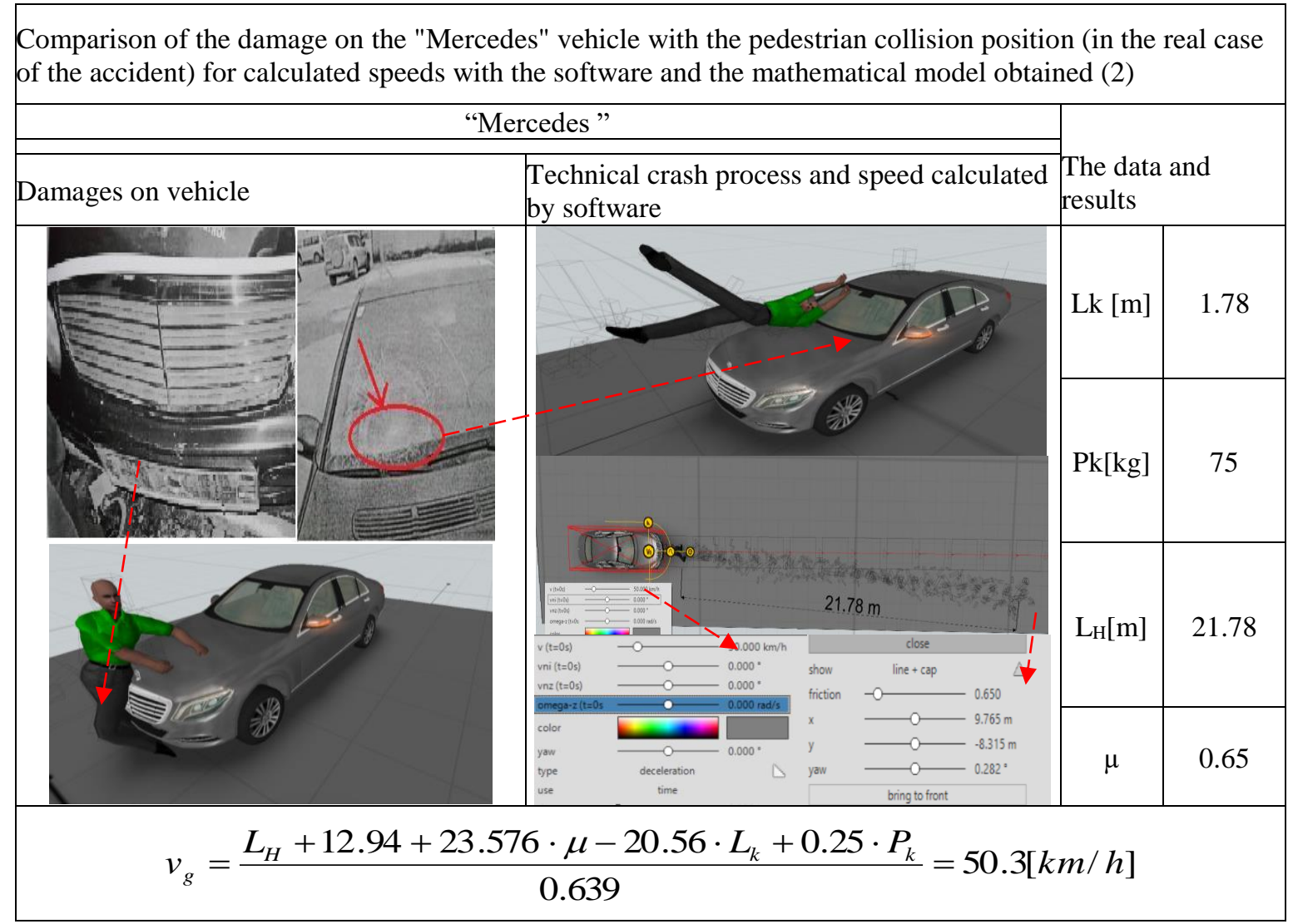

\footnotetext{
${ }^{2}$ Expression (2) is valid for these conditions:

- Frontal hit of pedestrian from vehicles "Mercedes E 220", "Peugeot 307" and "VW Golf V".

- Friction $\mu>0.35$.

- Vehicle in breaking process.

- Pedestrian moving in an indirect direction with the direction of movement of the vehicle.

- Frontal crash.
} 
Table 9. Test of model - Case of "Peugeot 307"

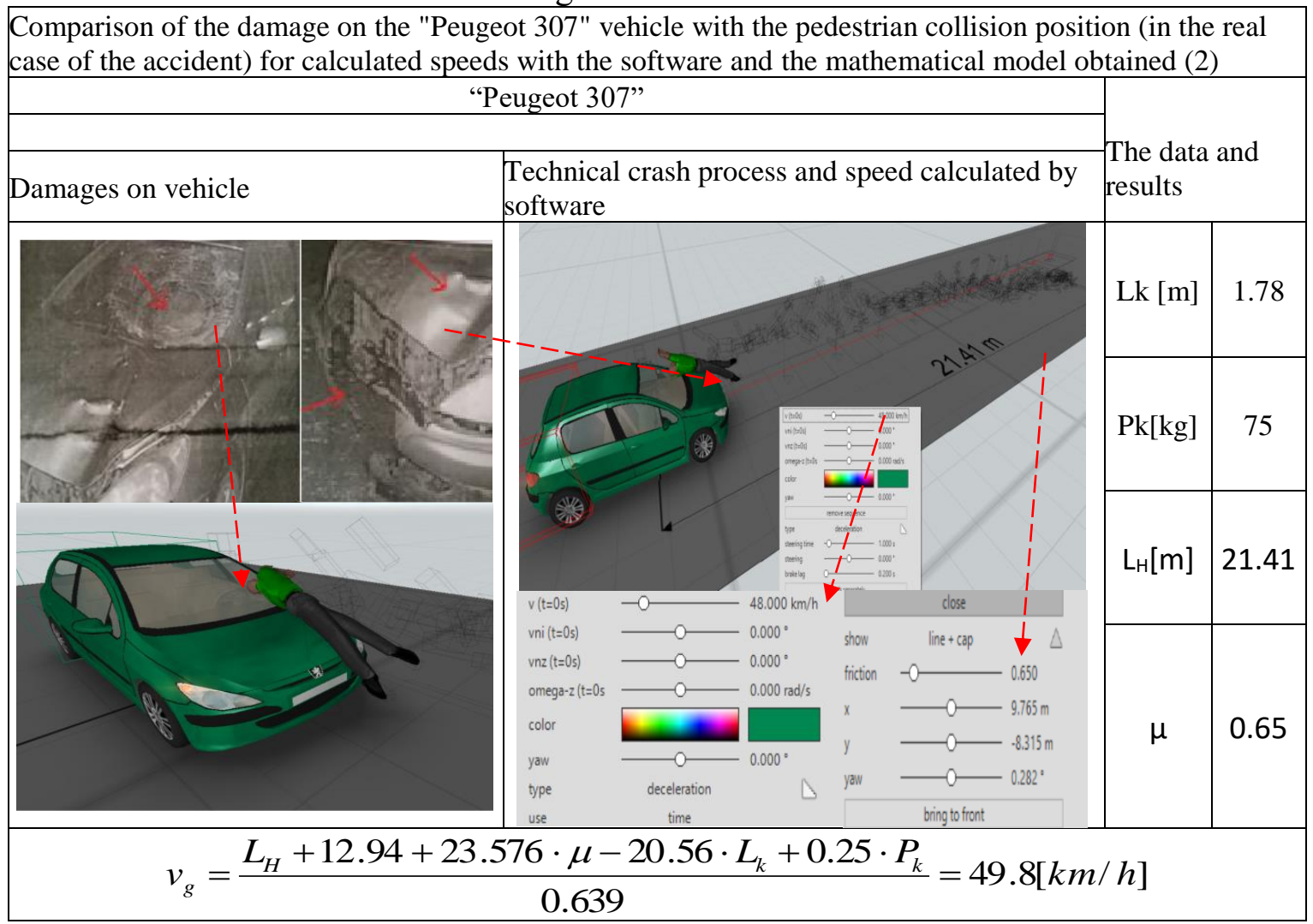




\section{CONCLUSION}

Obtained results from this research prove that following the primary pedestrian hit we have pedestrian high throwing ("flying"), and there is a loss of horizontal velocity as a result of pedestrian movement in the vertical direction (during rising and falling). However, this impact is quite small when calculating the speed and total length of pedestrian throwing. From the analysis through multiple linear regression using software, "SPSS" is the formulated mathematical model (2) which has played a significant role (Sig.=0.000). The validity of the formulated model, in the case of pedestrian hit by passenger vehicles (2), has been tested in concrete cases of accidents in practice and the results obtained in both cases were acceptable, with the possibility of a $+/-5 \%$ deviation from real results.

This model is recommended to be used in the case of frontal pedestrian hit by "Mercedes $\mathrm{E}$ 220", "VW Golf", and "Peugeot 307" vehicles and applies to certain conditions, including friction coefficient $\mu>0.35$, vehicle in breaking process, pedestrian on the move in the indirect direction with the direction of movement of the vehicle, and frontal impact (within the front part of the vehicle front).

\section{REFERENCE}

[1] Prof. dr. Mia Hubert, Prof. dr. Stefan Van Aelst, Linear Models Regression Analysis, Leuven, 2014 - 2015.

[2] G. Hoxha, R. Likaj, A. Kyçyku. Impact of angle determined by upper bumper ends and the front edge of the engine bonnet of vehicle profile in the throw distance of child. International Journal of Civil Engineering and Technology 2017 (8), No. 11, 42 - 51.

[3] D. Cochrane, G. H. Orcutt. Application of Least Squares Regressions to Relationships Containing Autocorrelation Error Term. Journal of American Statistical Association 1949 (44), No. 245, 32 - 61.

[4] J. Durbin. Estimating of Parameters in Time Series Regression Models, Journal of the Royal Statistics Society 1960 (22), Ser. B, 139 - 153.

[5] G. Hoxha, A. Shala, R. Likaj. Pedestrian crash model for vehicle speed calculation at road accident. International Journal of Civil Engineering and Technology 2017 (8), No. 9, 1093 - 1099.

[6] G. Hoxha, M. Bruçi, A. Shala, R. Likaj. Road friction impact in technical process of vehicle pedestrian crash and pedestrian throwing. 3rd international conference on advances in mechanical engineering from 19 - 21 December 2017, ISBN 978-605-954609-6, Yildiz Technical University, Istanbul, Turkey, 2017.

[7] G. Hoxha, R. Likaj, M. Bruçi. Regression mathematical model application by "r" software in determination of vehicle velocity for truck depend on throw pedestrian distance. 3rd 3rd international conference on advances in mechanical engineering from 19 - 21 December 2017, ISBN 978-605-9546-09-6, Yildiz Technical University, Istanbul, Turkey, 2017.

[8] Virtual-Crash, A Simulation Program for Vehicle Accidents. 2016.

[9] Vehicle vs. Child Pedestrian Collision - Full Scale Crash Tests and Mathematical Simulation, EVU 2010.

[10] Sen, A., Srivastava, Regression Analysis: Theory, Methods and Applications, Springer, New York, 1990. 
[11] P. Armitage. Statistical Methods in Medical Research, Oxford, Blackwell Scientific Publications, 1971.

[12] R. Gnandesikan. Methods for Statistical Analysis of Multivariate Observations, Wiley, NY., 1990.

[13] R. A. Johnson, D. W. Wichern. Applied Multivariate Statistical Analysis, Prentice Hall, NJ., 1992.

[14] G. Hoxha, A. Shala, R. Likaj. Vehicle speed determination in case of road accident by software method and comparing of results with the mathematical model, Journal of Mechanical Engineering - Strojnicky časopis 2017 (67), No. 2, 51 - 60. 